\title{
Pollination biology of the crypto-viviparous Avicennia species (Avicenniaceae)
}

\author{
A.J. Solomon Raju ${ }^{1}$, P.V. Subba Rao ${ }^{2}$, Rajendra Kumar ${ }^{3} \&$ S. Rama Mohan ${ }^{4}$ \\ ${ }^{1,4}$ Department of Environmental Sciences, Andhra University, Visakhapatnam, Andhra Pradesh 530003, India \\ ${ }^{2,3}$ Ministry of Environment and Forests, Paryavaran Bhavan, CGO Complex, Lodhi Road, New Delhi 110003, India \\ Email: ${ }^{1}$ solomonraju@gmail.com (corresponding author), ${ }^{2}$ pvsrao8@gmail.com, ${ }^{3}$ rajekr.72@gmail.com
}

Date of publication (online): 26 December 2012 Date of publication (print): 26 December 2012 ISSN 0974-7907 (online) | 0974-7893 (print)

Editor: Cleofas Cervancia

\section{Manuscript details:}

Ms \# 02919

Received 20 August 2011

Final received 06 December 2012

Finally accepted 06 December 2012

Citation: Raju, A.J.S., P.V.S. Rao, R. Kumar \& S.R. Mohan (2012). Pollination biology of the crypto-viviparous Avicennia species (Avicenniaceae). Journal of Threatened Taxa 4(15): 3377-3389.

Copyright: (c) A.J. Solomon Raju, P.V. Subba Rao, Rajendra Kumar \& S. Rama Mohan 2012 Creative Commons Attribution 3.0 Unported License. JoTT allows unrestricted use of this article in any medium for non-profit purposes, reproduction and distribution by providing adequate credit to the authors and the source of publication.

Author Details: See end of this article.

Author Contribution: The field work was done by all but it is mainly carried out by AJSR and SRM. All four authors have contributed in the preparation of manuscript but Prof. Raju is the main person among all.
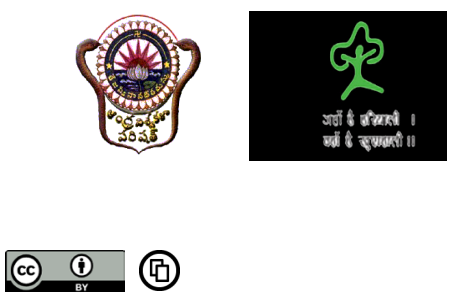

OPEN ACCESS | FREE DOWNLOAD
Abstract: Floral biology, sexual system, breeding system, pollinators, fruiting and propagule dispersal ecology of crypto-viviparous Avicennia alba BI., A. marina (Forsk.) Vierh. and $A$. officinalis L. (Avicenniaceae) were studied in Godavari mangrove forests of Andhra Pradesh State, India. All the three plant species initiate flowering following the first monsoon showers in June and cease flowering in late August. The flowers are hermaphroditic, nectariferous, protandrous, self-compatible and exhibit mixed breeding system. Self-pollination occurs even without pollen vector but fruit set in this mode is negligible. In all, the flowers are strictly entomophilous and the seedlings disperse through self-planting and stranding strategies.

Keywords: Avicennia species, entomophily, mixed breeding system protandry, selfcompatibility.

\section{INTRODUCTION}

The family Avicenniaceae comprises of only one genus Avicennia. The genus consists of at least eight tree species which grow in the intertidal zone of coastal mangrove forests and ranges widely throughout tropical and warm temperate regions of the world (Tomlinson 1986; Duke 1991). These species occupy diverse mangrove habitats, either within the normal tidal range or in back mangal and a high tolerance of hypersaline conditions. Of these, three species occur in Atlantic-East Pacific and five species in the Indo-West Pacific (Duke 1992). The East Africa and the Indo-Pacific species include $A$. officinalis, A. marina, A. alba, A. lanata, A. eucalyptifolia, A. balanophora and only the first three species reached the Indian subcontinent (Duke et al. 1998). A. officinalis has a wide range from southern India through Indo-Malaya to New Guinea and eastern Australia. A. marina has the broadest distribution, both latitudinally and longitudinally with a range from East Africa and the Red Sea along tropical and subtropical coasts of the Indian Ocean to the South China Sea, throughout much of Australia into Polynesia as far as Fiji, and south to the North Island of New Zealand (Tomlinson 1986). A. marina has the distinction of being the most widely distributed of all mangrove tree species. The ubiquitous presence in mangrove habitats around the world is due to the ability to grow and reproduce across a broad range of climatic, saline, and tidal conditions and to produce large numbers of buoyant propagules annually (Duke et al. 1998). A. alba has a wide distribution from India to Indochina, through the Malay Archipelago to the Philippines, New Guinea, New Britain, and northern Australia.

Tomlinson (1986) gave a brief account of the floral biology of Avicennia species. A. officinalis is self-compatible and occasionally self- 
pollinating. Self-pollination of individuals is unlikely due to protandry, but the sequence and synchrony of flowering, together with pollinator behaviour favours geitonogamy. Clarke \& Meyerscough (1991) reported that it is pollinated by a variety of insects in Australia. These authors also reported that A. marina is visited by ants, wasps, bugs, flies, bee-flies, cantherid beetles, and moths but the most common visitor is Apis mellifera. Tomlinson (1986) described that A. alba, A. marina and $A$. officinalis have very similar flowers and hence may well be served by the same class, if not the same species of pollinators; when these species grow together, there is evidence of non-synchrony in flowering times, which might minimize the competition for pollinators (probably bees) and at the same time spread the availability of nectar over a more extended period. This state of information in a preliminary mode provided the basis for taking up the present study on the pollination biology of crypto-viviparous Avicennia alba B1., A. marina (Forsk.) Vierh. and A. officinalis L. in Coringa mangrove forest of Andhra Pradesh. This paper describes the details of floral biology, sexual system, breeding system, pollinators and seedling ecology of these three Avicennia species. Further, these aspects have been discussed in the light of the existing relevant literature.

\section{MATERIALS AND METHODS}

\section{Floral biology}

The crypto-viviparous Avicennia alba, A. marina and $A$. officinalis (Avicenniaceae) occurring in Godavari mangrove forest $\left(16^{0} 30^{\prime}-17^{\circ} 00^{\prime} \mathrm{N} \& 82^{\circ} 10^{\prime}-\right.$ $\left.80^{\circ} 23^{\prime} \mathrm{E}\right)$ in the state of Andhra Pradesh, India, were used for the present study. The study was conducted during February 2008-April 2010. Regular field trips were conducted to track the flowering season in order to take up intensive field studies at weekly intervals during their flowering and fruiting season. The flower's morphological characteristics were described based on 25 flowers collected at random for each species. Quantification of the number of flowers produced per inflorescence and the duration of inflorescence were determined by tagging 10 inflorescences, which have not initiated flowering, selected at random and following them daily until they ceased flowering permanently. Anthesis was initially recorded by observing marked mature buds in the field. Later, the observations were repeated 3-4 times on different days during 0600-1400 $\mathrm{hr}$ in order to provide accurate anthesis schedule for each plant species. Similarly, the mature buds were followed for recording the time of anther dehiscence. The presentation pattern of pollen was also investigated by recording how anthers dehisced and confirmed by observing the anthers under a $10 \mathrm{x}$ hand lens. Twenty five mature but undehisced anthers was collected from different plants and placed in a petri dish. Later, each time a single anther was taken out and placed on a clean microscope slide $(75 \times 25 \mathrm{~mm})$ and dabbed with a needle in a drop of lactophenolaniline-blue. The anther tissue was then observed under the microscope for pollen, if any, and if pollen grains were not there, the tissue was removed from the slide. The pollen mass was drawn into a band, and the total number of pollen grains was counted under a compound microscope (40x objective, 10x eye piece). This procedure was followed for counting the number of pollen grains in each anther collected. Based on these counts, the mean number of pollen produced per anther was determined. The mean pollen output per anther was multiplied by the number of anthers in the flower for obtaining the mean number of pollen grains per flower. The characteristics of pollen grains were also recorded. The pollen-ovule ratio was determined by dividing the average number of pollen grains per flower by the number of ovules per flower. The value thus obtained was taken as pollen-ovule ratio (Cruden 1977). The presence of nectar was determined by observing the mature buds and open flowers. The volume of nectar from 20 flowers collected at random from each plant species was determined. Then, the average volume of nectar per flower was determined and expressed in $\mu$ l. The flowers used for this purpose were bagged at mature bud stage, opened after anthesis and squeezed nectar into micropipette for measuring the volume of nectar. Nectar sugar concentration was determined using a Hand Sugar Refractometer (Erma, Japan). For the analysis of sugar types, paper chromatography method described by Harborne (1973) was followed. Nectar was placed on Whatman No. 1 of filter paper along with standard samples of glucose, fructose and sucrose. The paper was run ascendingly for 24 hours with a solvent system of n-butanolacetone-water (4:5:1), sprayed with aniline oxalate spray reagent and dried at $120^{\circ} \mathrm{C}$ in an electric oven 
for 20 minutes for the development of spots from the nectar and the standard sugars. Then, the sugar types present and also the most dominant sugar type were recorded based on the area and colour intensity of the spot. Nectar amino acid types present in A. officinalis were also recorded as per the paper chromatography method of Baker \& Baker (1973). Nectar was spotted on Whatman No. 1 filter paper along with the standard samples of 19 amino acids, namely, alanine, arginine, aspartic acid, cysteine, cystine, glutamic acid, glycine, histidine, isolecuine, leucine, lysine, methionine, phenylalanine, proline, serine, threonine, tryptophan, tyrosine and valine. The paper was run ascendingly in chromatography chamber for 24 hours with a solvent system of n-butanol-glacial acetic acid-water (4:1:5). The chromatogram was detected with $0.2 \%$ ninhydrin reagent and dried at $85^{\circ} \mathrm{C}$ in an electric oven for 15 minutes for the development of spots from the nectar and the standard amino acids. The developed nectar spots were compared with the spots of the standard amino acids. Then, the amino acid types were recorded. The stigma receptivity was observed visually and by $\mathrm{H}_{2} \mathrm{O}_{2}$ test. In visual method, the stigma physical state (wet or dry) and the unfolding of its lobes were considered to record the commencement of receptivity; withering of the lobes was taken as loss of receptivity. $\mathrm{H}_{2} \mathrm{O}_{2}$ test as given in Dafni et al. (2005) was followed for noting stigma receptivity period.

\section{Pollinators}

The insect species visiting the flowers were observed visually and by using Olympus Binoculars (PX35 DPSR Model). There was no night time foraging activity at the flowers. Their foraging activity was confined to daytime only and were observed on a number of occasions on each plant species for their foraging behaviour such as mode of approach, landing, probing behaviour, the type of forage they collect, contact with essential organs to result in pollination and inter-plant foraging activity in terms of crosspollination. The foraging insects were captured during 1000-1200 hr on each plant species and brought them to the laboratory. For each insect species, 10 specimens were captured and each specimen was washed first in ethyl alcohol, the contents stained with aniline-blue on a glass slide and observed under microscope to count the number of pollen grains present. In case of pollen collecting insects, pollen loads on their corbiculae were separated prior to washing them. From this, the average number of pollen grains carried by each insect species was calculated to know the pollen carryover efficiency of different insect species.

\section{Breeding system}

Mature flower buds of some inflorescences on different individuals were tagged and enclosed in butter paper bags for breeding experiments. The number of flower buds used for each mode of pollination for each species was given in Table 1. The stigmas of flowers were pollinated with the pollen of the same flower manually by using a brush; they were bagged and followed to observe fruit set in manipulated autogamy. The flowers were fine-mesh bagged without hand pollination to observe fruit set in spontaneous autogamy. The emasculated flowers were handpollinated with the pollen of a different flower on the same plant; they were bagged and followed for fruit set in geitonogamy. The emasculated flowers were pollinated with the pollen of a different individual plant; they were bagged and followed for fruit set

Table 1. Results of breeding experiments in Avicennia species

\begin{tabular}{|c|c|c|c|}
\hline Breeding system & $\begin{array}{l}\text { No. of flowers } \\
\text { pollinated }\end{array}$ & $\begin{array}{l}\text { No. of flowers } \\
\text { set fruit }\end{array}$ & $\begin{array}{c}\text { Fruit set } \\
(\%)\end{array}$ \\
\hline \multicolumn{4}{|l|}{ Avicennia alba } \\
\hline Autogamy (bagged) & 40 & 7 & 17.5 \\
\hline $\begin{array}{l}\text { Autogamy (hand- } \\
\text { pollinated and bagged) }\end{array}$ & 20 & 8 & 40 \\
\hline Geitonogamy & 32 & 20 & 62.5 \\
\hline Xenogamy & 28 & 18 & 64.28 \\
\hline Open pollinations & 50 & 21 & 42 \\
\hline \multicolumn{4}{|l|}{ Avicennia marina } \\
\hline Autogamy (bagged) & 25 & 3 & 12 \\
\hline $\begin{array}{l}\text { Autogamy (hand- } \\
\text { pollinated and bagged) }\end{array}$ & 30 & 10 & 33.33 \\
\hline Geitonogamy & 25 & 10 & 40 \\
\hline Xenogamy & 25 & 17 & 68 \\
\hline Open pollinations & 45 & 25 & 55 \\
\hline \multicolumn{4}{|l|}{ Avicennia officinalis } \\
\hline Autogamy (bagged) & 56 & 12 & 21.42 \\
\hline $\begin{array}{l}\text { Autogamy (hand- } \\
\text { pollinated and bagged) }\end{array}$ & 35 & 15 & 42.85 \\
\hline Geitonogamy & 30 & 19 & 63.33 \\
\hline Xenogamy & 56 & 38 & 67.85 \\
\hline Open pollinations & 129 & 75 & 58.13 \\
\hline
\end{tabular}


in xenogamy. If fruit set is there, the percentage of fruit set was calculated for each mode. The flowers/ inflorescences were tagged on different plant species prior to anthesis and followed for fruit and seed set rate in open-pollinations.

\section{Seedling ecology}

Fruit maturation period and hypocotyl or seedling growth period prior to detachment from the parent tree were also recorded. Rose-ringed Parakeet feeding on fruit and/or hypocotyls of A. alba and A. marina was observed. A sample of fruits/hypocotyls was collected at random from these plant species to calculate the percentage of damage. Casual observations on seedling dispersal during low and high tide periods were made to record the dispersal mode.

\section{Photography}

Plant, flower and fruit details together with insect foraging activity on flowers were photographed with Nikon D40X Digital SLR (10.1 pixel) and TZ240 Stereo Zoom Microscope with SP-350 Olympus Digital Camera (8.1 pixel).

\section{RESULTS}

The three Avicennia species are evergreen trees with irregular spreading branches (Image 1a; 2a). Following monsoon showers in June, they initiate flowering and continue flowering until the end of August. Individual trees flower for 35 \pm 4 (Range 32-48) days in A. alba, $33 \pm 2$ (Range 32-35) days in A. marina and $38 \pm 4$ (Range 36-41) days in $A$. officinalis. In all the three species, the flowers are borne in terminal or axillary racemes/panicles (Image 1b; 2b; 2a). An inflorescence produces 52.34 26.96 flowers (Range 15-123) over a period of 25 days (Range 24-28) in A. alba, $47 \pm 13.97$ flowers (Range 26-76) over a period of 22 days (Range 15-22) in A. marina and 32 \pm 11 flowers (Range 9-35) over a period of 16-25 days in A. officinalis.

The flowers are sessile, small $(4 \mathrm{~mm}$ long; $3 \mathrm{~mm}$ diameter), orange yellow, fragrant, actinomorphic and bisexual in all the three species. They are slightly scented in A. alba and A. marina while foetid in A. officinalis. The flowers are $4 \mathrm{~mm}$ long and $3 \mathrm{~mm}$ diameter in $A$. alba, $6 \mathrm{~mm}$ long and $5 \mathrm{~mm}$ diameter in A. marina, and $10 \mathrm{~mm}$ long and $10 \mathrm{~mm}$ diameter in A. officinalis. Calyx is short, elliptic and has four ovate, green, pubescent sepals with hairs on the outer surface. Corolla has four thick, orange yellow ovate petals forming a short tube at the base. The petals are glabrous inside and hairy outside in A. marina while the adaxial petal is the broadest and shallowly bi-lobed in A. officinalis. Stamens are four, epipetalous, occur at the throat of the corolla. The anthers are basifixed, exserted, introrse and arranged alternate to petals. The ovary is $2 \mathrm{~mm}$ long in A. alba and A. marina while it is $7 \mathrm{~mm}$ long in A. officinalis. In all, it is conspicuously hairy and bicarpellary syncarpous with four imperfect locules and each locule contains one pendulous ovule. It is terminated with a 1-2 mm long glabrous style tapered to the bifid hairy stigma. The light yellow style and stigma arise from the center of the flower and stand erect throughout the flower life. In A. officinalis, the entire female structure is over-arched by stamens above. The style is bent, situated below the adaxial corolla lobe but not in the center of the flower.

The mature buds open throughout the day but most buds opening during 0900-1200 hr in A. alba (Image 1c,d), during 1000-1300 hr in A. marina (Image 2c,d) and during 0800-1100 $\mathrm{hr}$ in A. officinalis (Image $3 b-d)$. The petals slowly open and take 3-4 hours for complete opening to expose the stamens and stigma. The stamens bend inward overarching the stigma at anthesis and the all the anthers dehisce $1 / 2$ hour after anthesis by longitudinal slits. The stigma is well seated in the center of the flower. In A. officinalis, the stamens gradually stand erect and bend backwards over a period of three days. After anthesis, the stigma grows gradually and becomes bifid on the morning of the $2^{\text {nd }}$ day in $A$. alba (Image 1e,f) and A. marina (Image 2e,f) and on the $3^{\text {rd }}$ day in $A$. officinalis (Image $3 \mathrm{e}-\mathrm{h}$ ). The bifid condition of stigma is an indication of beginning of stigma receptivity and it remains receptive for two days in A. alba and A. marina, and for five days in $A$. officinalis. The stigmatic lobes recurve completely. The flower life is six days in A. alba, five days in A. marina and seven days in A. officinalis. The petals, stamens and stigma drop off while the calyx is persistent in all the three species.

The pollen production per anther is $1,967 \pm 31.824 .3$ (Range 1,929-2,010) in A. alba, 1,643.2 \pm 31.8 (Range $1,600-1,690$ ) in A. marina and 2,444 \pm 202.4 (Range 2,078-2,604) in A. officinalis. In all, the pollen grains are light yellow, granular, tricolporate, reticulate, muri 


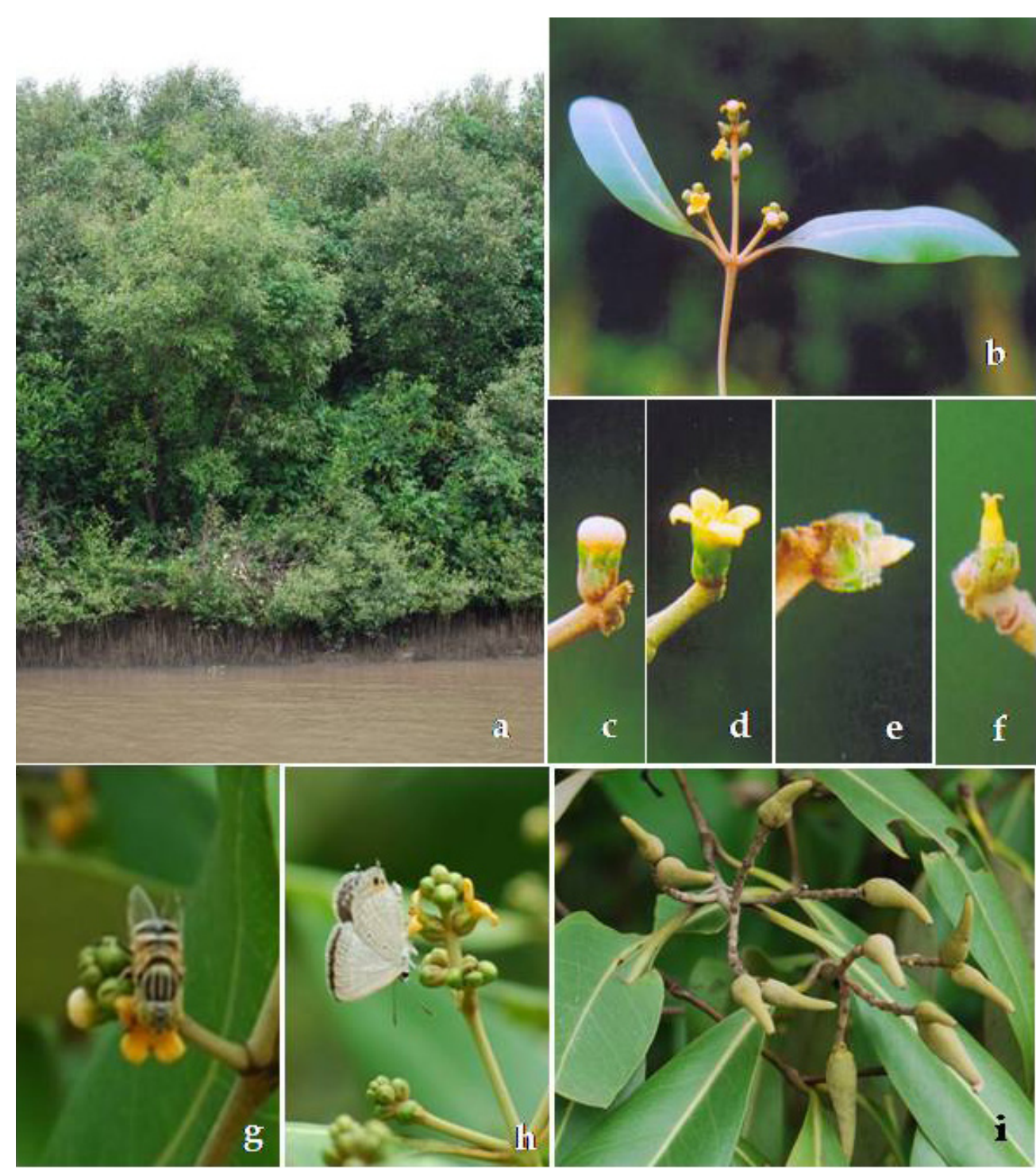

Image 1. Avicennia alba. a - Habitat; b - Flower unit; c - Mature Bud; $d$ - Flower; e - Stigma condition at anthesis; $f$ - Bifid stigma on the $2^{\text {nd }}$ day; $\mathrm{g}-\mathrm{i}$ - Flower visitors collecting nectar ( $\mathrm{g}$ - Fly (unidentified); $\mathrm{h}$ - Everes lacturnus; $\mathrm{i}$ - Fruit set in open-pollinations)

broad, flat, thick; lumina small irregularly shaped and colpi deeply intruding (Image 6a-c). Their size is $24.9 \mu \mathrm{m}$ in $A$. alba and $33.2 \mu \mathrm{m}$ in both $A$. marina and A. officinalis. The pollen-ovule ratio is $1,967: 1$ in A. alba, 1,643.2:1 in A. marina and 2,209.3:1 in A. officinalis. In all, the flowers begin nectar secretion along with anther dehiscence. The nectar secretion occurs in minute amount which is accumulated at the ovary base and on the yellow part of petals; the nectar glitters against sunlight. A flower produces $0.5 \pm 0.1$ (Range $0.4-0.7$ ) $\mu$ l of nectar with $40 \%$ sugar concentration in A. alba, $0.4 \pm 0.08$ (Range $0.3-0.5$ ) $\mu \mathrm{l}$ of nectar with $38 \%$ sugar concentration in A. marina and $0.65 \pm 0.09$ (Range $0.5-0.8$ ) $\mu \mathrm{l}$ of nectar with $39 \%$ sugar concentration in A. officinalis. The sugar types included glucose and fructose and sucrose with the first as dominant in A. alba and A. marina and the last as dominant in A. officinalis in which the nectar amino acids included aspartic acid, cysteine, alanine, arginine, serine, cystine, proline, lysine, glycine, glutamic acid, threonine and histidine.

In all three Avicennia species, the results of breeding systems indicate that the flowers are selfcompatible and self-pollinating. In A. alba, the fruit set is $17.5 \%$ in spontaneous autogamy, $40 \%$ in handpollinated autogamy, $62.5 \%$ in geitonogamy, $64.28 \%$ in xenogamy and $42 \%$ in open pollination (Image 1i) (Table 1). In A. marina, the fruit set is $12 \%$ in 


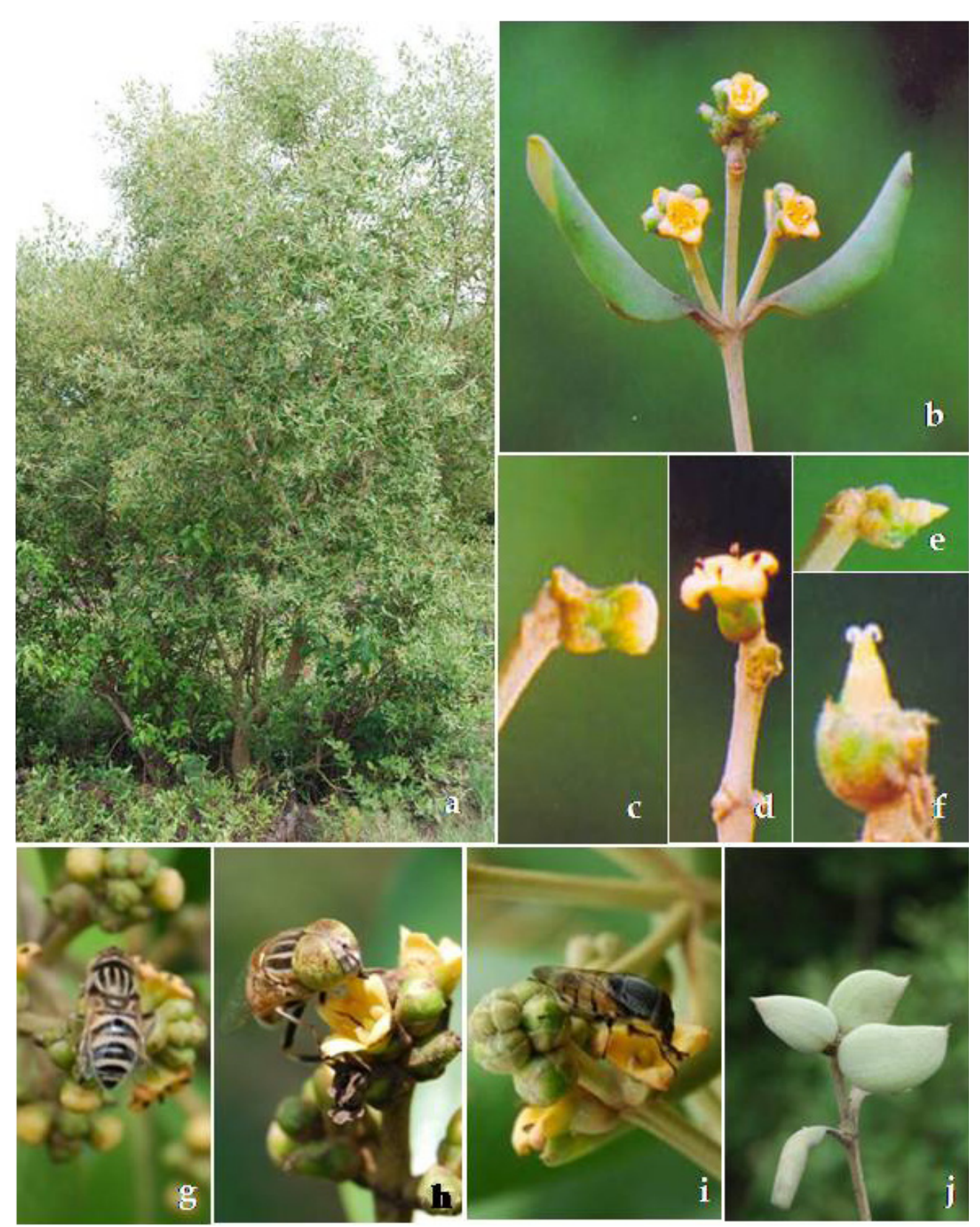

Image 2. Avicennia marina: a - Habitat; b - Flowering inflorescence; c - Mature bud; $d$ - Flower; e - Stigma condition at anthesis; $\mathrm{f}$ - Bifid stigma on the 2 nd day; $\mathrm{g}-\mathrm{j}$ - Flower visitors collecting nectar ( $\mathrm{g}$ - Unidentified fly; $\mathrm{h}$ - Eristalinus arvorum; $\mathrm{i}$ - Rhyncomya sp.; j - Fruit set in open-pollinations)

spontaneous autogamy, $33.33 \%$ in hand-pollinated autogamy, $40 \%$ in geitonogamy, $68 \%$ in xenogamy and $55 \%$ in open pollination (Image $2 \mathrm{j}$ ) (Table 1). In A. officinalis, the fruit set is $21.42 \%$ in spontaneous autogamy, $42.85 \%$ in hand-pollinated autogamy, $63.33 \%$ in geitonogamy, $67.85 \%$ in xenogamy and $58.13 \%$ in open pollination (Image 5a) (Table 1).

The insects foraged the flowers of Avicennia species during day time from $0700-1700 \mathrm{hr}$. They were Apis dorsata, A. florea, Nomia sp., Chrysomya megacephala, an unidentified fly (Image 1g), Danaus chrysippus and Everes lacturnus (Image 1h) in A. alba; Halictus sp., Chrysomya megacephala, Eristalinus arvorum (Image 2h), Rhyncomya sp. (Image 2i), an unidentified fly (Image 2g), Polistis humilis and Catopsilia pyranthe in A. marina; and Apis dorsata (Image 4a), Xylocopa pubescens, Xylocopa sp. (Image 4b,c), Eristalinus arvorum, Chrysomya megacephala (Image 4d), Sarcophaga sp. (Image 4e), Euploea core (Image 4j), Danaus chrysippus, D. genutia (Image 4h), 


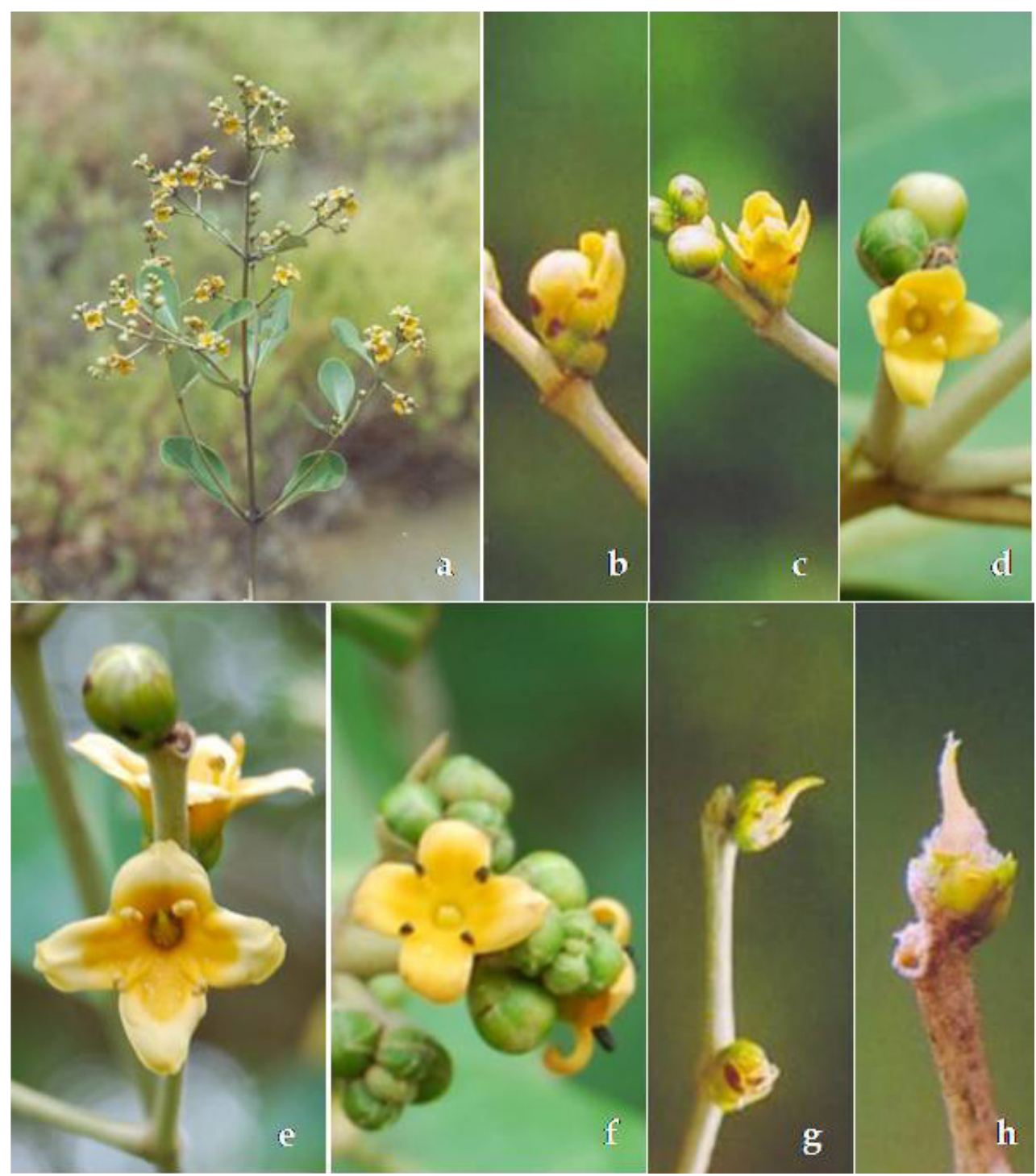

Image 3. Avicennia officinalis. a - Flowering branch; b-d - Different stages of anthesis; e - Flower with bent unreceptive stigma with dehisced anthers; $f$ - Flower with erect receptive stigma and withered anthers; $g$ - Unreceptive stigma; h - Receptive stigma.

Junonia lemonias, J. hierta (Image 4i), a fly (Image 4f) and a wasp (Image 4g) (unidentified) in A. officinalis. The flies visited the flowers in groups while all other insects visited individually. The bees were both pollen and nectar feeders while all other insects only nectar feeders. All the insects probed the flowers in upright position to collect the forage. In case of Xylocopa bees, they made audible buzzes while collecting nectar aliquots from the petals. Butterflies landed on the petals, stretched their proboscis to collect nectar aliquots on the petals and at the flower base. In this process, all the insects invariably touched the anthers and the stigma; the ventral side of all insects was found powdered with pollen. Further, the body washings of the all insect species revealed the presence of pollen; the average number of pollen grains per insect for each species varied from 67.6 to 336.2 ; in $A$. alba from 63.1 to 227.4, in A. marina, and from 73 to 550.2 in $A$. officinalis (Table 2). As the nectar is secreted in minute amounts, the insects made multiple visits to most of the flowers on a tree and moved frequently between trees to collect nectar. Such foraging behaviour was considered to be effecting self- and cross-pollination.

In all Avicennia species, pollinated and fertilized flowers initiate fruit development immediately and take about 4-6 weeks to produce mature fruits. In fertilized flowers, only one ovule produces seed. Fruit is a 1-seeded leathery pale green capsule with 

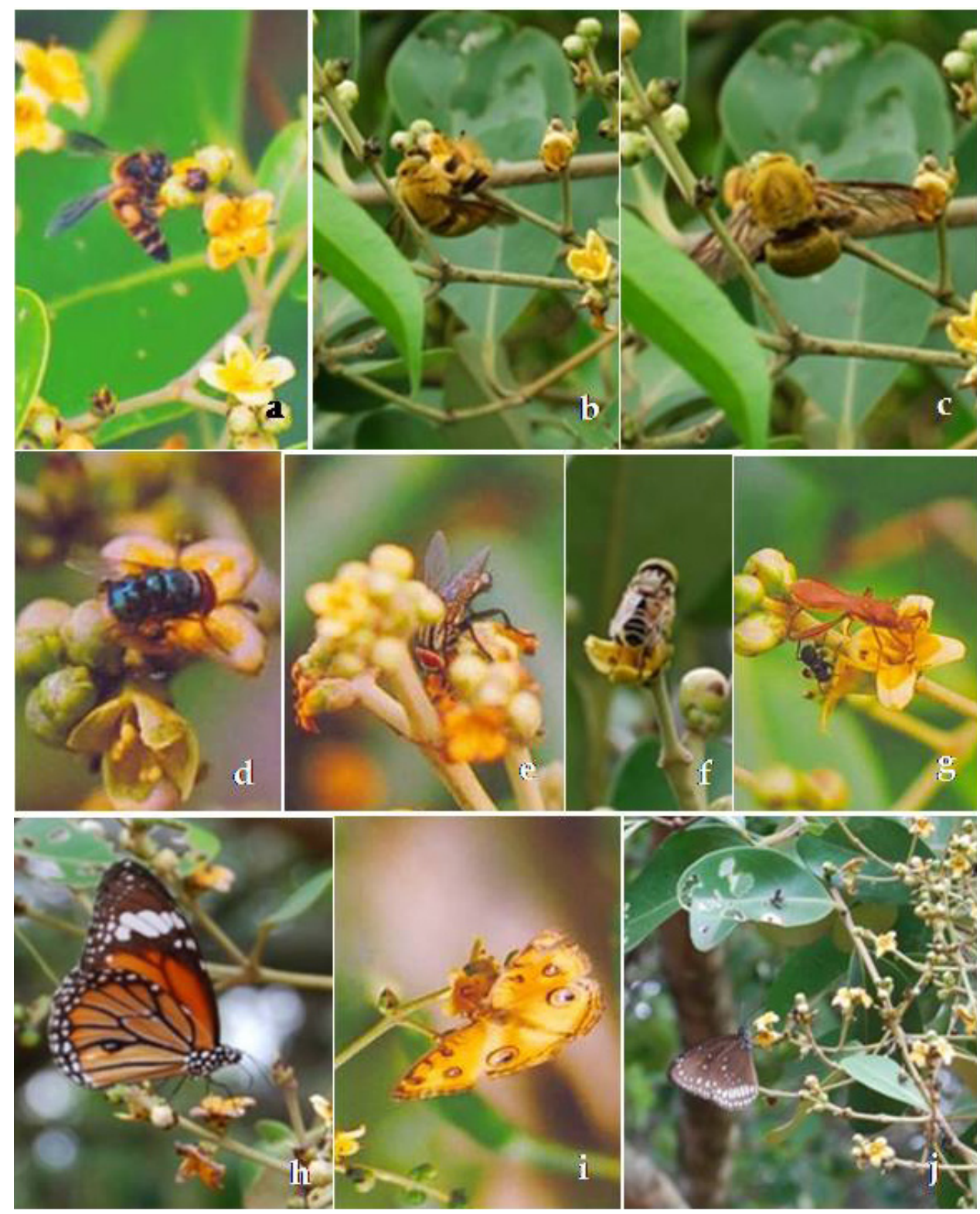

Image 4. Avicennia officinalis - Flower visitors. a - Apis dorsata; b \& c - Xylocopa sp.; d - Chrysomya megacephala; e - Sarcophaga sp.; f - Unidentified fly collecting nectar; g - Wasp (unidentified); h - Danaus genutia; i - Junonia hierta; j - Euploea core.

persistent reddish brown calyx. It is $40 \mathrm{~mm}$ long, $15 \mathrm{~mm}$ wide in $A$. alba, $30-35 \mathrm{~mm}$ long, $25 \mathrm{~mm}$ wide in A. marina and $30 \mathrm{~mm}$ long, $25 \mathrm{~mm}$ wide in $A$. officinalis. It is abruptly narrowed to a short beak and hairy throughout. Seed produces light green, hypocotyl which completely occupies the fruit cavity (Image 5b). Fruit set to the extent of $6 \%$ in A. alba and to the extent of $4 \%$ in A. marina was damaged by the Rose-ringed Parakeet Psittacula krameri which fed on the concealed hypocotyl in fruits and such fruits were found to be empty. In all three Avicennia species, the fruit together with hypocotyl falls off the mother plant; settles in the substratum immediately at low tide period when the forest floor is exposed; it floats in water and disperses by tidal currents at high tide period until settled somewhere in the soil. The radicle side of hypocotyl penetrates the soil and produces root system while plumule side produces new leaves and subsequent aerial system. The fruit pericarp detaches and disintegrates when plumular leaves are produced. 
Table 2. Pollen pick up efficiency of foraging insects on Avicennia species

\begin{tabular}{|c|c|c|c|}
\hline Insect species & $\begin{array}{c}\text { Sample } \\
\text { size }\end{array}$ & Range & Mean \pm S.D \\
\hline \multicolumn{4}{|l|}{ Avicennia alba } \\
\hline Apis dorsata & 10 & $219-476$ & $336.2 \pm 88.7$ \\
\hline A. florea & 10 & $129-327$ & $227.5 \pm 64.1$ \\
\hline Nomia sp. & 10 & $110-270$ & $200.6 \pm 50.7$ \\
\hline Chrysomya megacephala & 10 & $86-117$ & $101.5 \pm 11.0$ \\
\hline Fly (unidentified) & 10 & $56-98$ & $67.6 \pm 8.5$ \\
\hline Danaus chrysippus & 10 & 79-96 & $86.2 \pm 6.28$ \\
\hline Everes lacturnus & 10 & $57-87$ & $70.1 \pm 10.0$ \\
\hline \multicolumn{4}{|l|}{ Avicennia marina } \\
\hline Halictus sp. & 10 & $110-367$ & $215.2 \pm 78.8$ \\
\hline Chrysomya megacephala & 10 & $126-321$ & $227.4 \pm 66.7$ \\
\hline Rhyncomya sp. & 10 & $91-110$ & $99.7 \pm 7.5$ \\
\hline Eristalinus arvorum & 10 & $96-136$ & $118.2 \pm 13.6$ \\
\hline Polistis humilis & 10 & $56-73$ & $63.1 \pm 6.0$ \\
\hline Catopsilia pyranthe & 10 & $71-95$ & $83.8 \pm 8.61$ \\
\hline Unidentified fly & 10 & $66-106$ & $84.4 \pm 14.4$ \\
\hline \multicolumn{4}{|l|}{ Avicennia officinalis } \\
\hline Xylocopa pubescens & 10 & $452-789$ & $520.2 \pm 139.1$ \\
\hline Xylocopa sp. & 10 & $412-681$ & $550.2 \pm 125.2$ \\
\hline Apis dorsata & 10 & $325-541$ & $441.3 \pm 98.1$ \\
\hline Eristalinus arvorum & 10 & $142-251$ & $190.5 \pm 51.3$ \\
\hline Chrysomya megacephala & 10 & $98-131$ & $112.5 \pm 25.1$ \\
\hline Sarcophaga sp. & 10 & $105-120$ & $110.5 \pm 23.1$ \\
\hline Euploea core & 10 & $89-154$ & $124.5 \pm 32.6$ \\
\hline Danaus chrysippus & 10 & $56-110$ & $73.0 \pm 29.2$ \\
\hline D. genutia & 10 & $79-112$ & $94.3 \pm 24.6$ \\
\hline Junonia lemonias & 10 & $56-128$ & $98.6 \pm 13.2$ \\
\hline J. hierta & 10 & $91-120$ & $102.5 \pm 21.1$ \\
\hline Unidentified fly & 10 & $68-104$ & $81.0 \pm 20.4$ \\
\hline Unidentified wasp & 10 & $45-102$ & $85.1 \pm 12.5$ \\
\hline
\end{tabular}

\section{DISCUSSION}

All the three Avicennia species studied are principally polyhaline evergreen tree species. These tree species show flowering response to monsoon showers in June; the first monsoon showers seem to provide the necessary stimulus for flowering. Opler et al. (1976) and Ewusie (1980) have reported such a flowering response to light rains in summer season in a number of plants occurring in coastal environments. The flowering period extends until August in all the three species of Avicennia at the study sites, indicating
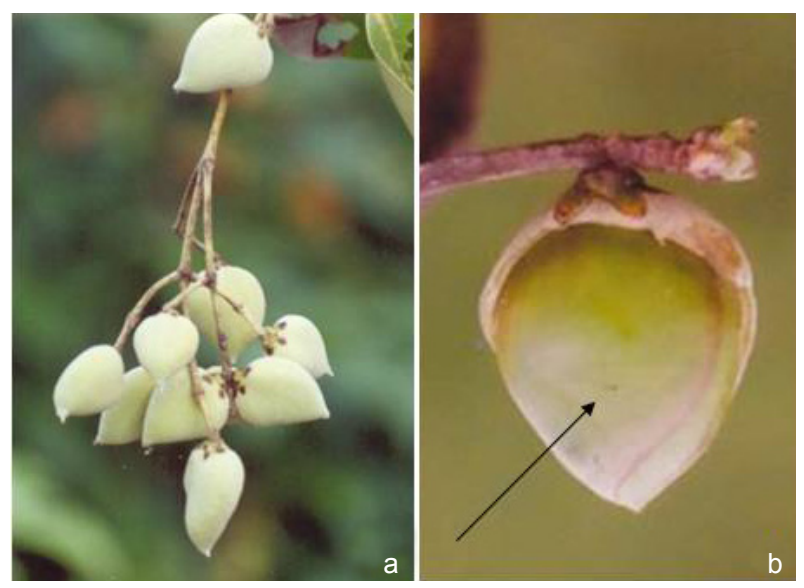

Image 5. Avicennia officinalis a - Fruit set in open-pollinations; b - Propagule.

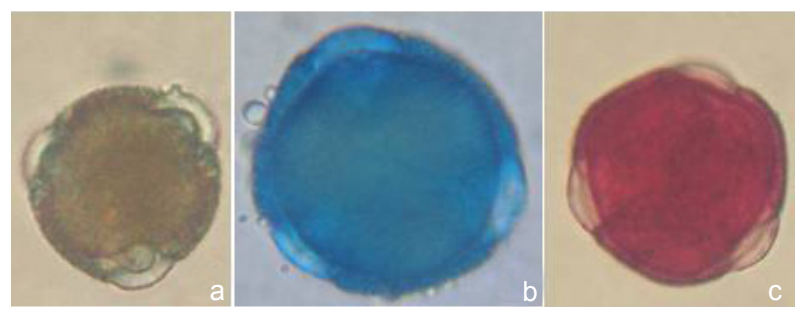

Image 6. Pollen grains of Avicennia species $\mathrm{a}$ - A. alba; $\mathrm{b}$ - A. marina; $\mathrm{c}$ - $A$. officinalis

that the flowering season is only for three months in a year. On the contrary, Wium-Andersen \& Christensen (1978) reported that in A. marina, flowering occurs during April-May. Further, Mulik \& Bhosale (1989) noted that the flowering in this species is from AprilSeptember. These authors also mentioned that the flowering occurs during March-July in A. officinalis. The variation in the schedule and length of flowering season in these species may be a response to local environmental conditions and to avoid competition for the available pollinators depending on the flowering seasons and population size of the constituent plant species which vary with each mangrove forest. In all the three species, the flowers are borne either in terminal or axillary inflorescences. But, the average number of flowers per inflorescence varies with each species; it is the highest in A. alba, moderate in A. marina and the least in $A$. officinalis. This flower production rate at inflorescence level may serve as an important taxonomic characteristic for the identification of these three species.

In all, the flowers are strongly protandrous and the stamens with dehisced anthers over-arch the stigma. 
The stigma shows post-anthesis growth. It is erect and seated in the center of the flower in $A$. alba and $A$. marina while it is bent and situated below the adaxial corolla lobe in A. officinalis. The erect stigma does not change its orientation throughout the flower life in A. alba and $A$. marina while the bent stigma becomes erect on day 3 . The stigma is bifid and appressed on the day of anthesis in all the three species; it remains in the same state also on day 2 in A. officinalis. The stigma commences receptivity by diverging in dorsi-ventral plane; it is receptive on day 2 and 3 in A. alba and A. marina, and on day 3, 4 and 5 in $A$. officinalis. The timing of commencement of stigma receptivity in $A$. officinalis strongly contradicts with an earlier report by Reddi et al. (1995) that the stigma attains receptivity three hours after anthesis with the bent stigma becoming erect. In A. officinalis, stigma behaviour is more advanced towards achieving crosspollination. In all the three species, self-pollination of individual flowers is unlikely on the day of anthesis due to protandry but the stamens with dehisced anthers over-arching the stigma may facilitate the fall of pollen on the receptive stigma when the latter attains receptivity. In effect, self-pollination may occur and the same is evidenced through fruit set in bagged flowers without manual self-pollination. Further, the sequence and synchrony of flowering, and pollinator behaviour at tree level contribute to geitonogamy (Clarke \& Meyerscough 1991). Hand-pollination results indicate that it is self-compatible and fruit set occurs through autogamy, geitonogamy and allogamy. The hermaphroditic flowers with strong protandry and long period of flower life in these species suggest that they are primarily adapted for cross-pollination. Clarke \& Meyerscough (1991) also reported that $A$. marina is protandrous, self-compatible and selfpollinating but the fruits resulting from spontaneous self-pollination showed a higher rate of maternal abortion reflecting an inbreeding depression. Coupland et al. (2006) reported that in A. marina, autogamy is most unlikely and emphasized the importance of pollen vectors to the reproductive success. This report is not in agreement with the results obtained in handpollination experiments on A. marina. Primack et al. (1981) suggested that protandry promotes out-crossing in mangroves, and that insect pollination facilitates it. They also suggested that geitonogamy in coastal colonizing plants would allow some fruit set in isolated colonizing plants, and thereafter the proportion of such pollinations would decline as pollen is transferred between plants. Pollen transfer between plants in such situations would still result in sibling mating. However, this is counteracted by dispersal of propagules, canopy suppression of seedlings and irregular yearly flowering among trees in close proximity. Clarke \& Meyerscough (1991) reported that in A. marina, some trees flower and fruit every year while some others do not flower every year. Those with complete canopy crops did not produce another large crop the following year. A similar pattern observed within a tree where fruit is produced on one branch and in the following year heavy flowering shifts to another branch. In the present study, all the three species of Avicennia flowered annually and the flowering is uniform on all branches within a tree. The study suggests that annual mass flowering, protandry, self-compatibility and self-pollination ability are important adaptations for Avicennia species to successfully colonize new areas and expand their distribution range as pioneer mangroves.

All the three species of Avicennia are hermaphroditic and have similar floral architecture. In all, the flowers are of open type and shallow with small aliquots of nectar which is exposed to rapid evaporation resulting in increased nectar sugar concentration. Corbet (1978) considered these characteristics as adaptations for fly pollination. Hexose-rich nectar is present in $A$. alba and $A$. marina while sucrose-rich nectar in $A$. officinalis. Hexose-rich nectar is the characteristic of fly- and short-tongued bee-flowers while sucrose-rich nectar is the characteristic of wasps and butterflies (Baker \& Baker 1982; 1983). The nectar sugar concentration is high and ranged from $38-40 \%$ in all the three Avicennia species. Cruden et al. (1983) reported that high nectar sugar concentration is the characteristic of bee-flowers while low nectar sugar concentration is the characteristic of butterfly-flowers. Baker \& Baker (1982) reported that the floral nectar is an important source of amino acids for insects. Dadd (1973) stated that insects require ten essential amino acids of which arginine, lysine, threonine and histidine are present in the nectar of $A$. officinalis. He also reported that proline and glycine are essential amino acids for some insects; these two amino acids are also present in the nectar of $A$. officinalis. He further stated that other amino acids such as alanine, aspartic acid, 
glutamic acid, glycine and serine while not essential do increase insect growth. All these amino acids are also present in the nectar of A. officinalis. Shiraishi \& Kuwabara (1970) reported that proline stimulates salt receptor cells in flies. Goldrich (1973) reported that histidine elicits a feeding response while glycine and serine invoke an extension of the proboscis. The nectars of $A$. alba and $A$. marina have not been analyzed for amino acids and hence this aspect has not been discussed.

The flowers of all the three species of Avicennia with differences in their structural and functional characteristics as stated above have been able to attract different classes of insects - bees, wasps, flies and butterflies. Of these, bees while collecting pollen and nectar, and all other insects while collecting nectar effected pollination and their ability to carry pollen has been evidenced in their body washings. Flies are known as short distance fliers and such behaviour largely results in autogamy or geitonogamy. Since these flies visit the flowers as large groups, there is automatically a competition for the available nectar which is secreted in small aliquots on the petals of all the three Avicennia species. In consequence, they shift from tree to tree in search of nectar forage and in the process they contribute to both self- and crosspollination. All other insects are habitual long-distance fliers and effect both self- and cross-pollination. An earlier report by Subba Reddi et al. (1995) showed that only bees and flies are the pollinators of $A$. officinalis at the study sites. Tomlinson (1986) mentioned that Avicennia flowers are bee-pollinated. In Australia, A. marina is pollinated by ants, wasps, bugs, flies, bee-flies, cantharid beetles and moths (Clarke \& Meyerscough 1991).

Tomlinson (1986) documented that A. alba, A. marina and $A$. officinalis have very similar flowers and hence may well be served by the same class, if not by the same species of pollinators; when these species grow together, there is evidence of nonsynchrony in flowering times, which might minimize the competition for pollinators (probably bees) and at the same time spread the availability of nectar over a more extended period. In the present study, these plant species grow together, flower synchronously but served by the same classes of insects. There is no competition for pollen among different classes of insects since only bees collect pollen while all other classes of insects collect only nectar. Fly pollinators with their swarming behaviour at the flowers may enable the plant species to set fruit to the extent possible. Flies and bees are usually consistent and reliable when compared to wasps and butterflies. Therefore, the study shows flies and bees play an important role in the success of sexual reproduction in all the three species of Avicennia. Despite being pollinated by different classes of insect pollinators and having the ability to self-pollinate even in the absence of insect activity as evidenced in bagged flowers, the natural fruit set stands at $42-58 \%$ in these plant species. This low fruit set could be due to maternal abortion of self-pollinated fruits as reported by Clarke \& Meyerscough (1991), non-availability of sufficient pollen to receptive stigmas due to pollen feeding activity of bees and the nutritional resource constraint to the maternal parent. Coupland et al. (2006) while reporting on fruit set aspects of A. marina in Australia mentioned that fruit set is not pollinator limited but resource limited.

In Avicenniaceae, the flowers have been reported to contain four ovules (Tomlinson 1986). In the present study, all the three species of Avicennia are 4-ovuled but only one ovule develops into mature seed in fertilized and fruited flowers as in Rhizophoraceae. The production of one-seeded fruits may be due to maternal resource constraint or maternal regulation of seed set. Fruits grow and mature within 5-6 weeks in A. alba and within 4 weeks in the other two Avicennia species. The duration of fruit maturation is not in agreement with the report of Wium-Andersen \& Christensen (1978) who stated that the development from flower bud to mature fruit takes a few months. The calyx is persistent in all the three species but it does not expand to enclose the growing fruit. Therefore, the calyx has no role in sheltering or protecting the fruit. As the fruit is a leathery capsule, it does not require any protection from the calyx.

The single seed formed in the fruit is not dormant and germinates immediately to produce chlorophyllous seedling which remains within the fruit, while still on the maternal parent. This is a characteristic of "crypto-viviparous" species; similar situation exists in the genera such as Aegiceras, Aegialitis, Nypa and Pelliciera (Tomlinson 1986). In all these species, fruit is the propagule; the seedling occupies the fruit cavity. The chlorophyllous seedling actively photosynthesizes 
while the maternal parent supplies the water and necessary nutrients (Selvam \& Karunagaran 2004). In Avicennia species, the propagules are small, light and the entire embryo is buoyant after detachment from the maternal parent. Gradually, the fruit pericarp is lost exposing the leathery succulent cotyledons to tidal water. Rabinowitz (1978) reported that A. marina has an absolute requirement for a stranding period in order to establish since its propagules always float in tidal water. He also felt that the propagules must have freedom from tidal disturbance in order to take hold in the soil. In consequence, this species is restricted to the higher ground portions of the swamp where the tidal inundation is less frequent. In the present study, Avicennia species exhibit self-planting strategy at low tide and stranding strategy at high tide. However, their seedlings disperse widely in tidal water but establishment is mainly stationed in the polyhaline zone. Duke et al. (1998) reported that Avicennia seedlings disperse widely and are genetically uniform throughout their range. In the study areas, genetic studies are required to know whether all the three species studied are genetically uniform. When the seedlings settle, radicle penetrates the sediment before the cotyledons unfold. The first formal leaves appear one month after germination and the second pair one to two months (Wium-Andersen \& Christensen 1978).

Coupland et al. (2006) reported that Avicennia propagules are a rich source of nutrients and attract a diverse range of insect predators which in turn influence the rate of seedling maturation. Resource constraints and insect predation on developing fruit and seedling may both act to reduce fruit set. In A. marina and $A$. germinans, the seedlings tend to be high in nutritive value and have relatively few chemical defenses (Smith 1987; McKee 1995). These species tend to exhibit a pattern of very rapid initial predation (Allen et al. 2003). In the present study, seedling predation has been evidenced in A. alba and A. marina only; in both the species, the Rose-ringed Parakeet Psittacula krameri attacks propagules prior to their detachment from the maternal parent. Seedling predation by crabs after detachment from the maternal parent may be expected since different species of crabs have been found in the study areas. Therefore, seedling predation may reduce the success of seedling establishment in all the three species of Avicennia.

\section{REFERENCES}

Allen, J.A., K.W. Krauss \& R.D. Hauff (2003). Factors limiting the intertidal distribution of the mangrove species Xylocarpus granatum. Oecologia 135: 110-121.

Baker, H.G. \& I. Baker (1973). Some anthecological aspects of evolution of nectar-producing flowers, particularly amino acid production in nectar, pp. 243-264. In: Heywood, V.H. (ed.). Taxonomy and Ecology, Academic Press, London.

Baker, H.G. \& I. Baker (1982). Chemical constituents of nectar in relation to pollination mechanisms and phylogeny, pp. 131-171. In: Nitecki, H.M. (ed.). Biochemical aspects of Evolutionary Biology, University of Chicago Press, Chicago.

Baker, H.G. \& I. Baker (1983). A brief historical review of the chemistry of floral nectar, pp. 126-152. In: Bentley, B. \& T. Elias (eds.). The Biology of Nectaries, Columbia University Press, New York.

Clarke, P.J. \& P.J. Meyerscough (1991). Floral biology and reproductive phenology of Avicennia marina in south eastern Australia. Australian Journal of Botany 39: 283293.

Corbet, S.A. (1978). Nectar, insect visits, and the flowers of Echium vulgare, pp. 21-30. In: Richards, A.J. (ed.). The Pollination of Flowers by Insects, Academic Press, London.

Coupland, G.T., I.P. Eric \& K.A. McGuinness (2006). Floral abortion and pollination in four species of tropical mangroves from northern Australia. Aquatic Botany 84: 151-157.

Cruden, R.W. (1977). Pollen-ovule ratios: a conservative indicator of breeding systems in flowering plants. Evolution 31: $32-46$

Cruden, R.W., H.M. Hermann \& S. Peterson (1983). Patterns of nectar production and plant-pollinator co-evolution, pp. 80-125. In: Bentley, B. \& T. Elias (eds.). The Biology of Nectaries. Columbia University Press, New York.

Dadd, R.H. (1973). Insect nutrition: current developments and metabolic implications. Annual Review of Entomology 18: 881-420.

Dafni, A., P.G. Kevan \& B.C. Husband (2005). Practical Pollination Biology. Enviroquest Ltd., Ontario, 590pp.

Duke, N.C. (1991). A systematic revision of the mangrove genus Avicennia (Avicenniaceae) in Australasia. Australian Journal of Systematic Botany 4: 299-324.

Duke, N.C. (1992). Mangrove floristics and biogeography, pp. 63-100. In: Robertson, A.J. \& D.M. Alongi (eds.). Tropical Mangrove Ecosystems, Coastal and Estuarine Studies Series. American Geographical Union, Washington.

Duke, N.C., A.H.B. John, J.A. Goodall \& E.R. Ballment (1998). A genetic structure and evolution of species in the mangrove genus Avicennia (Avicenniaceae) in the Indowest pacific. Evolution 52: 1612-1626.

Ewusie, J.Y. (1980). Tropical Ecology. Heinemann Educational Books Ltd., London, 205pp.

Goldrich, N.R. (1973). Behavioural responses of Phormia 
regina (Meigen) to labellar stimulation with amino acids. Journal of General Physiology 61: 74-88.

Harborne, J.B. (1973). Phytochemical Methods. Chapman and Hall, London, $302 \mathrm{pp}$.

McKee, K.L. (1995). Mangrove species distribution and propagule predation in Belize: An exception to the dominance-predation hypothesis. Biotropica 27: 334 345.

Mulik, N.G. \& L.J. Bhosale (1989). Flowering phenology of the mangroves from the west coast of Maharashtra. Journal of the Bombay Natural History Society 86: 355-359.

Opler, P.A., G.W. Frankie \& H.G. Baker (1976). Rainfall as a factor in the release, timing and synchronization of anthesis by tropical trees and shrubs. Journal of Biogeography 3: 231-236.

Primack, R.B., N.C. Duke \& P.B. Tomlinson (1981). Floral morphology in relation to pollination ecology in five Queensland coastal plants. Austrobaileya 4: 346355.

Rabinowitz, D. (1978). Dispersal properties of mangrove propagules. Biotropica 10: $47-57$.

Reddi, C.S., A.J.S. Raju \& S.N. Reddy (1995). Pollination ecology of Avicennia officinalis L. (Avicenniaceae). Journal of Palynology 31: 253-260.

Selvam, V. \& V.M. Karunagaran (2004). Ecology and Biology of Mangroves. Coastal Wetlands: Mangrove Conservation and Management. Orientation Guide 1. M.S. Swaminathan Research Foundation, Chennai, 158pp.

Shiraishi, A. \& M. Kuwabara (1970). The effects of amino acids on the labellar hair chemosensory cells of the fly. Journal of General Physiology 56: 768-782.

Smith, T.J. (1987). Seed predation in relation to tree dominance and distribution in mangrove forests. Ecology 68: 266-273.

Tomlinson, P.B. (1986). The Botany of Mangroves. Cambridge University Press, New York, 413pp.

Wium-Andersen, S. \& B. Christensen (1978). Seasonal growth of mangrove trees in southern Thailand. II. Phenology of Bruguiera cylindrica, Ceriops tagal, Lumnitzera littorea and Avicennia marina. Aquatic Botany 5: 383-390.
Author Details:

Prof. A.J. Solomon Raju is Head in the Department of Environmental Sciences, Andhra University, Visakhapatnam. He is presently working on endemic and endangered plant species in southern Eastern Ghats forests with financial support from UGC and MoEF, and on mangroves of Andhra Pradesh with financial support from MoEF.

DR. P.V. SubBA RaO is Assistant Director working in the Ministry of Environment \& Forests, Government of India, New Delhi.

Mr. RaJendRa KUMAR is Research Officer working in the Ministry of Environment \& Forests, Government of India, New Delhi, and also pursuing PhD (part-time) under Prof. A.J. Solomon Raju.

DR. S. RAMA MOHAN is Assistant Director, Department of Horticulture, Government of Andhra Pradesh. He has worked under Prof. A.J. Solomon Raju for $\mathrm{PhD}$ during which he did part of the work reported in this paper. 